\title{
AN OPTIMIZATION-BASED HEURISTIC FOR A CAPACITATED LOT-SIZING MODEL IN AN AUTOMATED TELLER MACHINES NETWORK
}

\author{
${ }^{1}$ Supatchaya Chotayakul, ${ }^{1}$ Peerayuth Charnsetthikul, ${ }^{1}$ Juta Pichitlamken and ${ }^{2}$ John Kobza
}

\author{
${ }^{1}$ Department of Industrial Engineering, Faculty of Engineering, \\ Kasetsart University, Chatuchak, Bangkok 10900, Thailand \\ ${ }^{2}$ Department of Industrial Engineering, Faculty of Engineering, \\ The University of Tennessee, Knoxville, Tennessee 37996, US
}

Received 2013-09-12; Revised 2013-09-23; Accepted 2013-10-01

\begin{abstract}
This research studies a cash inventory problem in an ATM Network to satisfy customer's cash needs over multiple periods with deterministic demand. The objective is to determine the amount of money to place in Automated Teller Machines (ATMs) and cash centers for each period over a given time horizon. The algorithms are designed as a multi-echelon inventory problem with single-item capacitated lot-sizing to minimize total costs of running ATM network. In this study, we formulate the problem as a Mixed Integer Program (MIP) and develop an approach based on reformulating the model as a shortest path formulation for finding a near-optimal solution of the problem. This reformulation is the same as the traditional model, except the capacity constraints, inventory balance constraints and setup constraints related to the management of the money in ATMs are relaxed. This new formulation gives more variables and constraints, but has a much tighter linear relaxation than the original and is faster to solve for short term planning. Computational results show its effectiveness, especially for large sized problems.
\end{abstract}

Keywords: Shortest Path Formulation, Multi-Echelon Inventory, ATM Network, Capacitated Lot-Sizing Model

\section{NTRODUCTION}

This research focuses on cash management for an ATM network in Thailand. ATM planning and replenishment to serve customer's cash needs are a key service of commercial banks. Customers can access banking services of their bank accounts in order to make cash withdrawals from the machines, which are placed over the country. Banks must employ several employees and employees' time to oversee the network and make decisions about the cash management system to ensure that they have the right cash levels at the right locations; therefore, they incur high operating costs such as transport cost, insurance, servicing costs and inventory cost (Simutis et al., 2008). Many experts believe the amount of cash maintained in ATMs exceeds $15-20 \%$ of customer need and about $35-60 \%$ of overall costs of the cash management system come from running the ATMs (Simutis et al., 2007). Thus, the problem of reducing the overall costs of running the ATMs is significant. The objective is to find the amount of cash to be refilled in ATMs and cash centers over a fixed period of time foe short term planning.

In the present paper, we propose "a multi-echelon inventory problem with Single-Item Capacitated LotSizing (SICLS)" formulation in order to minimize the ordering cost (refilling cost) and holding cost (opportunity cost) of cash inventory at ATMs and cash centers and to satisfy time-varying demands. We formulate the problem as a Mixed Integer Programming (MIP) for the resulting optimization of this problem. However it usually requires much more computational Kasetsart University, Chatuchak, Bangkok 10900, Thailand 
effort for real-world problems with large sample size. The problem is known to be NP-hard (Florian and Klein, 1972; Chubanov et al., 2008).

Many mathematical programming-based procedures used to solve the single-item capacitated lot-sizing model and were studied by many researchers. Wakinaga and Sawaki (2008) studied a dynamic programming approach for solving the dynamic lot size model for the case where single-item is produced and shipped by an overseas export company. They explored the problem with the constraint of production and shipment capacity so as to minimize the total cost over the finite planning horizon with deterministic demands. Berk et al. (2008) developed the dynamic programming formulation of the single item lot-sizing problem for a walm/cold process with finite capacity and possible lost sales and solved the problem with a polynomial solution algorithm based on the lost-sales-improvements of the full commitment problem. They obtained the optimal solution in case of positive setup times and the heuristic solutions in another cases.

Akbalik and Pochet (2009) proposed a new class of valid inequalities for the single-item capacitated lot sizing problem with step-wise production costs that they called mixed flow cover inequalities which is derived from the integer flow cover inequalities. Computational results show the efficiency of the new class mixed flow cover compared to the existing methods. Akbalik and Penz (2009) proposed an exact pseudo-polynomial dynamic programming algorithm to solve a special case of the single-item capacitated lot-sizing problem. Zhang et al. (2012) formulated the capacitated lot sizing problem in closed-loop supply chain considering setup costs, product returns and remanufacturing as a mixed integer program and proposed a Lagrangian relaxationbased solution approach to solve the problem. Two polynomial time algorithms for solving the constant capacitated lot sizing problem was presented by Akbalik and Rapine (2012).

For this study, we use the Shortest Path Reformulation (SPR) approach to reformulate the MIP of the multi-echelon inventory problem of SICLS for finding a solution. The shortest path reformulation approach was originally proposed by Eppen and Martin (1987) for solving the Multi-Item Capacitated Lot-Sizing (MICLS) problems. Hindi (1995) developed this approach using column generation on the uncapacitated version of the problem for solving the single-item capacitated lot-sizing problem. Wu et al. (2011) extended this approach to formulate the capacitated multi-level lot-sizing with backlogging and found that the linear programming relaxation provides good lower bounds on the optimal solution value and develop an approach based on reformulating the model as a Shortest Path Reformulation (SPR) for finding a near optimal solution.

The main idea of this study is to improve the MIP formulation of the problem using a reformulation based on the shortest path algorithm so that commercial solvers like CPLEX or Gulobi are able to solve practical instance of cash inventory problem for short term planning.

The rest of this article is organized in five sections. In Section 2 we explain the materials and methods to use for this study. In Section 3 we present comparison of the results of computational experiments between the two algorithms and the discussion was shown in Section 4. Section 5 contains the conclusions and the future research.

\section{MATERIALS AND METHODS}

\subsection{Problem Description}

Cash management for ATMs is one of the important problems a bank faces. The costs of operating and maintaining ATMs are very high and include the cost of the ATM machines, renting facilities, networking, administration and the opportunity cost for depositing money in the machine. An ATM transaction is an expensive financial transaction and the banks can make little profit from it, but they must still support this service for customers. In this case, since the administrative cost and the opportunity cost for storing money in the machine are the crucial management costs that banks can plan and manage, we focus on the development of an efficient ATM cash inventory policy that satisfies customer demand.

Inventory costs occur when the bank stores money in the ATMs and the cash centers, which are places for storage of cash moving to or from the central bank (Bank of Thailand; BOT) through commercial banks and cash centers to the bank branches and self-service devices (ATMs) to satisfy customer cash demand. The amount of money to place in ATMs and cash centers depends on future unknown demands. If the amount of money in ATMs and cash centers is higher than the customer demand, then an opportunity cost of holding cash will occur. The cost of money or the opportunity cost will be associated with interest rates and may also include insurance costs for the money held in the ATM. But if the amount of money is lower than the customer demand, the bank incurs a shortage cost. Thus, the development of an advanced algorithm for ATM 
services to reduce the overall costs of running the ATMs is very important for banks.

In Thailand a bank must pay an interchange fee when its customers use another bank's ATM. The bank may also have to pay a refill cost associated with replenishing the ATM. If the ATM is inside a bank branch, then there is no cost of moving cash to and from the ATM. However, if the ATM is not in a bank branch, then a refilling cost or ordering cost is incurred when the money in the ATM is refilled. This cost is independent of the amount of money refilled.

The goal of this research is to determine how much money to store in ATMs and cash centers and the frequency of cash replenishment in each period based on banks in Thailand so that all demands are satisfied with minimum total costs for running the ATMs. Customer demand at cash ATM is assumed to be known and deterministic and shortages are not allowed. Note that, since there is no cost for restocking cash at the ATMs in local branches they are considered part of cash management in branches and are not considered for this problem.

\subsection{Problem Formulation}

This part presents mathematical model to solve the cash inventory problem in ATM networks by determining the amount of money to place in ATMs and cash centers for each period over a given time horizon. We formulate the problem as a MIP formulation of a multi-echelon inventory problem with single-item capacitated lot-sizing. Parameters and decision variables regarding the model are listed as follows:

\section{Parameters}

$\mathrm{T}=$ Number of time periods in the planning horizon

$\mathrm{t}=$ Time period index; $\mathrm{t}=1,2, \ldots, \mathrm{T}$

$\mathrm{m}=$ The total number of cash centers

$\mathrm{i}=$ Cash center index; $\mathrm{i}=1,2, \ldots, \mathrm{m}$

$\mathrm{n}_{\mathrm{i}}=$ The total number of ATMs in each cash center i

$\mathrm{j}=$ ATM index; $\mathrm{j}=1,2, \ldots, \mathrm{n}_{\mathrm{i}}$

$\mathrm{D}_{\mathrm{ijt}}=$ Amount cash demanded of ATM j managed by cash center $\mathrm{i}$ at period $\mathrm{t}$

$\mathrm{q}_{\mathrm{i}}=$ Refilling cost (Baht per trip) from the bank to cash center i

$\mathrm{o}=$ Opportunity cost (per day) of money stored in cash center or ATM

$\mathrm{r}_{\mathrm{ij}}=$ Refilling cost (Baht per trip) from cash center $\mathrm{i}$ to ATM j $\mathrm{a}_{\mathrm{ij}}=$ Sufficiently large number for an upper bound of a cash order for each ATM $\mathrm{j}$ from cash center i

$b_{i}=$ Sufficiently large number for an upper bound of a cash order for each cash center i

$\mathrm{C}_{\mathrm{ATM}}=$ Available cash storage capacity of each ATM

$\mathrm{C}_{\mathrm{CC}}=$ Available cash storage capacity of each cash center

\section{Decision Variables}

$\mathrm{Q}_{\mathrm{it}}=$ Order quantity of cash center $\mathrm{i}$ at period $\mathrm{t}$

$\mathrm{X}_{\mathrm{ijt}}=$ Order quantity of ATM $\mathrm{j}$ delivered by cash center $\mathrm{i}$ at period $\mathrm{t}$

$\mathrm{J}_{\mathrm{it}}=$ Inventory level of money stored in cash center $\mathrm{i}$ at the end of period $t$

$\mathrm{I}_{\mathrm{ijt}}=$ Inventory level of money stored in ATM j managed by cash center $i$ at the end of period $t$

$\gamma_{i t}=$ Binary setup variable indicating where order quantity is allowed for cash center $\mathrm{i}$ in period $\mathrm{t}$ $(=1$, if cash is refilled in cash center $i$ in period $t$, 0 otherwise)

$\delta_{\mathrm{ijt}}=$ Binary setup variable indicating where order quantity is allowed for ATM $\mathrm{j}$ under cash center $\mathrm{i}$ in period $\mathrm{t}(=1$, if cash is refilled in ATM $\mathrm{j}$ managed by cash center $i$ in period t, 0 otherwise)

Our formulation of the problem is described by the following mathematical program Equation 1:

$$
\begin{aligned}
& \text { Minimize Total Cost }=\sum_{\mathrm{i}=1}^{\mathrm{m}} \sum_{\mathrm{t}=1}^{\mathrm{T}}\left(\mathrm{q}_{\mathrm{i}} \gamma_{\mathrm{it}}+\mathrm{oJ}_{\mathrm{it}}\right)+ \\
& \sum_{\mathrm{i}=1}^{\mathrm{m}} \sum_{\mathrm{j}=1}^{\mathrm{n}_{\mathrm{i}}} \sum_{\mathrm{t}=1}^{\mathrm{T}}\left(\mathrm{r}_{\mathrm{ij}} \delta_{\mathrm{ijt}}+\mathrm{oI}_{\mathrm{ijt}}\right)
\end{aligned}
$$

Subject to Equation 2:

$$
\begin{aligned}
& \mathrm{I}_{\mathrm{ij}(\mathrm{t}-1)}+\mathrm{X}_{\mathrm{ijt}}-\mathrm{I}_{\mathrm{ijt}}=\mathrm{d}_{\mathrm{ijt}} ; \forall \mathrm{i} \in\{1 \ldots \mathrm{m}\}, \mathrm{j} \in\left\{1 \ldots \mathrm{n}_{\mathrm{i}}\right\}, \mathrm{t} \in\{1 \ldots \mathrm{T}\} \\
& \mathrm{X}_{\mathrm{ijt}}-\left(\alpha_{\mathrm{ij}} \delta_{\mathrm{ijt}}\right) \leq 0 ; \forall \mathrm{i} \in\{1 \ldots \mathrm{m}\}, \mathrm{j} \in\left\{1 \ldots \mathrm{n}_{\mathrm{i}}\right\}, \mathrm{t} \in\{1 \ldots \mathrm{T}\} \\
& \mathrm{X}_{\mathrm{ijt}}-\mathrm{I}_{\mathrm{ij}(\mathrm{t}-1)} \leq \mathrm{C}_{\mathrm{ATM}} ; \forall \mathrm{i} \in\{1 \ldots \mathrm{m}\}, \mathrm{j} \in\left\{1 \ldots \mathrm{n}_{\mathrm{i}}\right\}, \mathrm{t} \in\{1 \ldots \mathrm{T}\} \\
& \mathrm{J}_{\mathrm{i}(\mathrm{t}-1)}+\mathrm{Q}_{\mathrm{it}}-\mathrm{J}_{\mathrm{it}}=\sum_{\mathrm{j}=1}^{\mathrm{n}_{\mathrm{i}}} \mathrm{X}_{\mathrm{ijt}} ; \forall \mathrm{i} \in\{1 \ldots \mathrm{m}\}, \mathrm{t} \in\{1 \ldots \mathrm{T}\} \\
& \mathrm{Q}_{\mathrm{it}}-\left(\mathrm{b}_{\mathrm{i}} \gamma_{\mathrm{it}}\right) \leq 0 ; \forall \mathrm{i} \in\{1 \ldots \mathrm{m}\}, \mathrm{t} \in\{1 \ldots \mathrm{T}\} \\
& \mathrm{Q}_{\mathrm{it}}-\mathrm{J}_{\mathrm{i}(\mathrm{t}-1)} \leq \mathrm{C}_{\mathrm{CC}} ; \forall \mathrm{i} \in\{1 \ldots \mathrm{m}\}, \mathrm{t} \in\{1 \ldots \mathrm{T}\}
\end{aligned}
$$




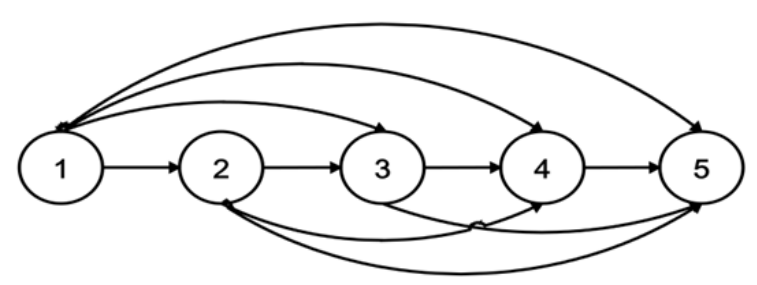

Fig. 1. Shortest path representation of the lot sizing dynamic program for 1 item and 4 periods

$$
\begin{aligned}
& \mathrm{X}_{\mathrm{ijt}}, \mathrm{I}_{\mathrm{ijt}} \geq 0 ; \forall \mathrm{i} \in\{1 \ldots \mathrm{m}\}, \mathrm{j} \in\left\{1 \ldots \mathrm{n}_{\mathrm{i}}\right\}, \mathrm{t} \in\{1 \ldots \mathrm{T}\} \\
& \mathrm{Q}_{\mathrm{it}}, \mathrm{J}_{\mathrm{it}} \geq 0 ; \forall \mathrm{i} \in\{1 \ldots \mathrm{m}\}, \mathrm{t} \in\{1 \ldots \mathrm{T}\} \\
& \delta_{\mathrm{ijt}} \in 0,1 ; \forall \mathrm{i} \in\{1 \ldots \mathrm{m}\}, \mathrm{j} \in\left\{1 \ldots \mathrm{n}_{\mathrm{i}}\right\}, \mathrm{t} \in\{1 \ldots \mathrm{T}\} \\
& \gamma_{\mathrm{it}} \in 0,1 ; \forall \mathrm{i} \in\{1 \ldots \mathrm{m}\}, \mathrm{t} \in\{1 \ldots \mathrm{T}\}
\end{aligned}
$$

The objective function (1) is to minimize the total costs for allocating cash in cash centers and ATMs (refilling costs and opportunity cost). Constraints (2) and (5) are the inventory balance constraints for ATMs and cash centers, respectively. Constraints (3) and (6) forces a set-up cost to be incurred for periods with positive ordering cash of each ATM and each center; it requires $\delta_{\mathrm{ijt}}$ to be 1 if $\mathrm{X}_{\mathrm{ijt}}$ is non-zero and it requires $\gamma_{\mathrm{it}}$ to be 1 if $\mathrm{Q}_{\mathrm{it}}$ is non-zero. Constraints (4) and (7) represent the capacity constraints: the overall cash in ATM must remain lower than the available capacity. Constraints (8) and (9) are non-negative variables for order quantities and inventory level. Constraints (10) and (11) specify the binary setup variables.

For the large sizes of problem, the MIP formulation cannot solve or is very hard to solve in reasonable computational time. Thus, we develop an approach based on reformulating the model as a shortest path problem for finding a near-optimal solution.

\subsection{The Shortest Path Reformulation}

Eppen and Martin (1987) presented the shortest path formulation approach to reformulate the capacitated lotsizing problems based on a network diagram shown in Fig. 1. The new formulation proposes variables $Z_{\mathrm{ijk}}$ that is the fraction of the accumulated demand from period $\mathrm{k}$ to period 1. Each node of network flow represents the period 1, 2, 3, 4 and a dummy period 5 . The arc between nodes $\mathrm{k}$ and 1 means the choice of ordering the whole demand from period $\mathrm{k}$ to period $1-1$ in period $\mathrm{k}$. The solution is to find the shortest path from node 1 to node 5 .
We now reformulate the MIP as described in Equation (1-11) as a SP reformulation. Only constraints that are related to capacity constraints, setup constraints and inventory balance constraints for managing ATMs will be relaxed. The rest of the constraints will not change from the original model. The decision variables and SP reformulation are as follows.

\section{Decision Variables}

$\mathrm{Z}_{\mathrm{ijkl}}$ fraction of the total demand refilled in period $\mathrm{k}$ for demand in periods $\mathrm{k}$ to 1 of ATM $\mathrm{j}$ managed by cash center I Equation (12-26):

$$
\begin{aligned}
& \text { Minimize Total Cost }=\sum_{\mathrm{i}=1}^{\mathrm{m}} \sum_{\mathrm{t}=1}^{\mathrm{T}}\left(\mathrm{q}_{\mathrm{i}} \gamma_{\mathrm{it}}+\mathrm{o}_{\mathrm{t}} \mathrm{J}_{\mathrm{it}}\right)+ \\
& \sum_{\mathrm{i}=1}^{\mathrm{m}} \sum_{\mathrm{j}=1}^{\mathrm{n}_{\mathrm{i}}} \sum_{\mathrm{t}=1}^{\mathrm{T}}\left(\mathrm{r}_{\mathrm{ij}} \delta_{\mathrm{ijt}}+\mathrm{o}_{\mathrm{t}} \mathrm{I}_{\mathrm{ijt}}\right)
\end{aligned}
$$

Subject to:

$$
\begin{aligned}
& \sum_{\mathrm{l}=2}^{\mathrm{T}+1} \mathrm{Z}_{\mathrm{ij} 11}=1 ; \forall \mathrm{i} \in\{1 \ldots \mathrm{m}\}, \mathrm{j} \in\left\{1 \ldots \mathrm{n}_{\mathrm{i}}\right\} \\
& \sum_{\mathrm{k}=1}^{\mathrm{l}=1} \mathrm{Z}_{\mathrm{ijkl}}=\sum_{\mathrm{k}=1+1}^{\mathrm{T}+1} \mathrm{Z}_{\mathrm{ijkl}} ; \forall \mathrm{l} \in\{2 \ldots \mathrm{T}\}, \forall \mathrm{i} \in(1 \ldots \mathrm{m}), \mathrm{j} \in\left\{1 \ldots \mathrm{n}_{\mathrm{i}}\right\} \\
& \sum_{1=k+1}^{\mathrm{T}+1} \mathrm{Z}_{\mathrm{ijk}} \leq \delta_{\mathrm{ijk}} ; \forall \mathrm{k} \in\{1 \ldots \mathrm{T}\}, \forall \mathrm{i} \in(1 \ldots \mathrm{m}), \mathrm{j} \in\left\{1 \ldots \mathrm{n}_{\mathrm{i}}\right\} \\
& \sum_{1=k+1}^{T+1}\left(\sum_{u=k}^{1-1} d_{i j u}\right) Z_{i j k l}=X_{i j t} ; \\
& \forall \mathrm{k} \in\{1 \ldots \mathrm{T}\}, \forall \mathrm{i} \in(1 \ldots \mathrm{m}), \mathrm{j} \in\left\{1 \ldots \mathrm{n}_{\mathrm{i}}\right\} \\
& \mathrm{I}_{\mathrm{ij}(\mathrm{t}-1)}+\mathrm{X}_{\mathrm{ijt}}-\mathrm{I}_{\mathrm{ijt}}=\mathrm{d}_{\mathrm{ijj}} ; \forall \mathrm{i} \in(1 \ldots \mathrm{m}), \mathrm{j} \in\left\{1 \ldots \mathrm{n}_{\mathrm{i}}\right\}, \mathrm{t} \in\{1 \ldots \mathrm{T}\} \\
& \mathrm{X}_{\mathrm{ijt}}+\mathrm{I}_{\mathrm{ij}(\mathrm{t}-1)} \leq \mathrm{C}_{\mathrm{ATM}} ; \forall \mathrm{i} \in(1 \ldots \mathrm{m}), \mathrm{j} \in\left\{1 \ldots \mathrm{n}_{\mathrm{i}}\right\}, \mathrm{t} \in\{1 \ldots \mathrm{T}\} \\
& \mathrm{J}_{\mathrm{i}(\mathrm{t}-\mathrm{l})}+\mathrm{Q}_{\mathrm{it}}-\mathrm{J}_{\mathrm{it}}=\sum_{\mathrm{j}=1}^{\mathrm{n}_{\mathrm{i}}} \mathrm{X}_{\mathrm{ijt}} ; \forall \mathrm{i} \in(1 \ldots \mathrm{m}), \mathrm{t} \in\{1 \ldots \mathrm{T}\} \\
& \mathrm{Q}_{\mathrm{it}}-\left(\mathrm{b}_{\mathrm{i}} \gamma_{\mathrm{it}}\right) \leq 0 ; \forall \mathrm{i} \in(1 \ldots \mathrm{m}), \mathrm{t} \in\{1 \ldots \mathrm{T}\} \\
& \mathrm{Q}_{\mathrm{it}}+\mathrm{J}_{\mathrm{i}(\mathrm{t}-1)} \leq \mathrm{C}_{\mathrm{CC}} ; \forall \mathrm{i} \in(1 \ldots \mathrm{m}), \mathrm{t} \in\{1 \ldots \mathrm{T}\} \\
& \mathrm{X}_{\mathrm{ijt}}, \mathrm{I}_{\mathrm{ijt}} \geq 0 ; \forall \mathrm{i} \in(1 \ldots \mathrm{m}), \mathrm{j} \in\left(1 \ldots \mathrm{n}_{\mathrm{i}}\right), \mathrm{t} \in\{1 \ldots \mathrm{T}\} \\
& \mathrm{Q}_{\mathrm{it}}, \mathrm{J}_{\mathrm{it}} \geq 0 ; \forall \mathrm{i} \in(1 \ldots \mathrm{m}), \mathrm{t} \in\{1 \ldots \mathrm{T}\}
\end{aligned}
$$




$$
\begin{aligned}
& \gamma_{\mathrm{it}} \in 0,1 ; \forall \mathrm{i} \in(1 \ldots \mathrm{m}), \mathrm{t} \in\{1 \ldots \mathrm{T}\} \\
& \delta_{\mathrm{ijk}} \in 0,1 ; \forall \mathrm{i} \in(1 \ldots \mathrm{m}), \mathrm{j} \in\left\{1 \ldots \mathrm{n}_{\mathrm{i}}\right\}, \mathrm{t} \in\{1 \ldots \mathrm{T}\} \\
& \mathrm{Z}_{\mathrm{ijk} l} \geq 0 ; \forall \mathrm{k} \in\{1 \ldots \mathrm{T}\}, 1 \in\{2 \ldots \mathrm{T}+1\}, \mathrm{i} \in(1 \ldots \mathrm{m}), \mathrm{j} \in\left\{1 \ldots \mathrm{n}_{\mathrm{i}}\right\}
\end{aligned}
$$

The objective function (12) is to minimize the total costs for allocating cash in cash centers and ATMs (refilling costs and opportunity cost). Constraint (13) ensures that there is no more than one arc outgoing from node 1 for refilling each ATM. Constraint (14) ensures that if cash is placed in ATM in period 1, it must exist in period $1+1$. Constraint (15) forces the setup binary variables $\delta_{i j k}$ to be one whenever money is refilled in ATM j managed by cash center $\mathrm{i}$ in period t. Constraint (16) is used to find the order quantity for ATM j managed by cash center $i$ at period t. Constraint (17) is used to find the inventory level of money stored in ATM $\mathrm{j}$ managed by cash center $\mathrm{i}$ at the end of period $\mathrm{t}$. Constraints (17)-(25) are identical to Constraints (2), (4)(11) in the original model. Constraint (26) enforces the non-negativity requirements for variables.

\subsection{Computational Tests}

This part presents the computational tests to evaluate the performance of problem formulations: the MIP formulation and the optimization-based heuristic approach (shortest path reformulation), to find good optimal and heuristic solutions.

These algorithms are tested on a computer with an Intel(R) Core(TM) i5-2400 3.10GHz CPU and 8GB RAM. Two solution methods are compared using the computational time and the quality of the solutions in various configurations of the ATMs network problem. The numbers of ATMs are varied as 10, 20, 30, 40, 50, 100, 150, 200, 250, 300, 500 and 1,000 ATMs with 5 cash centers and 7 time periods for testing performance of the proposed approach. The numerous data sets are randomly generated upon request. The optimization software Gurobi Optimization (http://www.gurobi.com/) was used to find the solutions for both algorithms.

\section{RESULTS}

We use running time to evaluate the quality of the algorithms. Table 1 reports a solution, a solution time (CPU time in seconds) and a percent difference of the solutions of the two approaches for different numbers of ATMs with fixed number of cash centers and time periods.

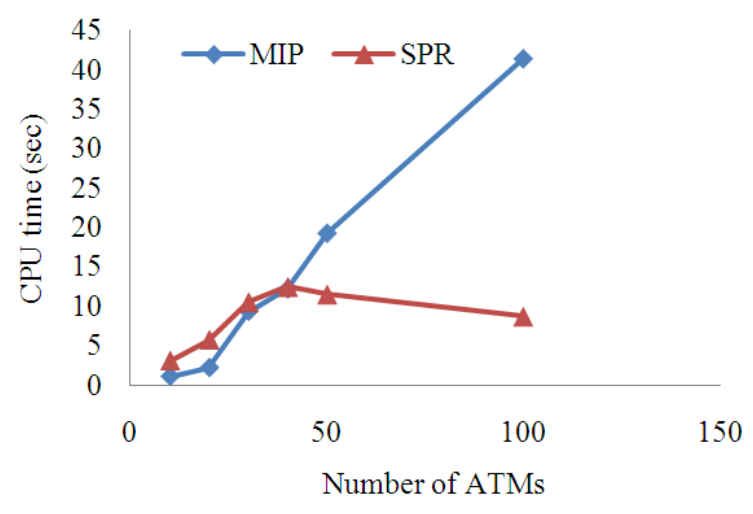

Fig. 2. Comparison of CPU Time between the MIP

\begin{tabular}{|c|c|c|c|c|c|}
\hline \multirow[b]{2}{*}{$\begin{array}{l}\text { No. of } \\
\text { ATMs }\end{array}$} & \multicolumn{2}{|l|}{ MIP } & \multicolumn{2}{|l|}{ SPR } & \multirow{2}{*}{$\begin{array}{l}\% \text { Diff. } \\
\text { of total } \\
\text { costs }\end{array}$} \\
\hline & $\begin{array}{l}\text { Total } \\
\text { costs }\end{array}$ & $\begin{array}{l}\mathrm{CPU} \\
\text { time }(\mathrm{sec})\end{array}$ & $\begin{array}{l}\text { Total } \\
\text { costs }\end{array}$ & $\begin{array}{l}\text { CPU } \\
\text { time (sec) }\end{array}$ & \\
\hline 10 & 82,799 & 1.08 & 82,849 & 3.01 & 0.060 \\
\hline 20 & 109774 & 2.19 & 109785 & 5.68 & 0.010 \\
\hline 30 & 128,539 & 9.34 & 128,539 & 10.48 & 0.000 \\
\hline 40 & 156,312 & 12.18 & 156,316 & 12.45 & 0.003 \\
\hline 50 & 186,800 & 19.25 & 186,841 & 11.48 & 0.030 \\
\hline 100 & 323,111 & 41.43 & 323,257 & 8.63 & 0.050 \\
\hline 150 & 456,847 & 15556 & 456,847 & 13.07 & 0.000 \\
\hline 200 & - & $>8 \mathrm{~h}$ & 588,687 & 20.99 & - \\
\hline 250 & - & - & 706,289 & 23.38 & - \\
\hline 300 & - & - & 839,144 & 27.80 & - \\
\hline 500 & - & - & $1,325,148$ & 47.69 & - \\
\hline 1000 & - & - & $2,631,580$ & 106.60 & - \\
\hline
\end{tabular}
formulation and the SPR approach

Table 1. Comparison between the MIP formulation and the SPR approach

Figure 2 illustrates a graph comparison of CPU Time between the MIP formulation and the SPR approach.

\section{DISCUSSTION}

From Table 1, it can be seen that the MIP formulation can only solve small sizes of the problem and spends more computational time when the numbers of ATMs increase (Fig. 2). As the SPR algorithm can give solutions in less computational time although the problem is large. It was solved in a few minutes with 1,000 ATMs. Comparing the total costs of the two methods found that the SPR approach gave the optimal or close to optimal solution.

\section{CONCLUSION}

This research presented a new reformulation based on a shortest path formulation approach to solve a multi- 
echelon inventory problem with single-item capacitated lot-sizing that was implemented in a cash inventory problem in an ATM network in Thailand. Computational experiments show that the proposed approach provides very good solutions for problems of large realistic sizes in short computational time for a short planning horizon compared with the traditional mixed integer program approach.

There are two directions for future research. First, the model should be extended to the capacitated lotsizing with a stochastic demand environment. Second, in this study, we focus on allocating cash to the cash centers and the ATMs with certain delivery routes. However, cash delivery routes depend on the set of replenishment decisions in a given time period. Therefore the refilling costs are not fixed by certain delivery routes but are determined by the aggregated length of the optimal routes. For future study, the mixed-integer inventory and the vehicle routing problem should be combined to derive the optimal cash management strategy.

\section{ACKNOWLEDGEMENT}

This study was financially supported by the Department of Industrial Engineering, the Texas Tech University during 2008-2009.

\section{REFERENCES}

Akbalik, A. and B. Penz, 2009. Exact methods for single-item capacitated lot sizing problem with alternative machines and piece-wise linear production costs. Int. J. Product. Econ., 119: 367379. DOI: 10.1016/j.ijpe.2009.03.010

Akbalik, A. and C. Rapine, 2012. Polynomial time algorithms for the constant capacitated single-item lot sizing problem with stepwise production cost. Operat. Res. Lett., 40: 390-397. DOI: 10.1016/j.orl.2012.05.003

Akbalik, A. and Y. Pochet, 2009. Valid inequalities for the single-item capacitated lot sizing problem with step-wise costs. Eur. J. Operat. Res., 198: 412-434. DOI: $10.1016 /$ j.ejor.2008.08.026

Berk, E., A.O. Toy and O. Hazir, 2008. Single item lotsizing problem for a warm/cold process with immediate lost sales. Eur. J. Operat. Res., 187: 1251-1267. DOI: 10.1016/j.ejor.2006.06.070
Chubanov, S., M.Y. Kovalyov and E. Pesch, 2008. A single-item economic lot-sizing problem with a nonuniform resource: Approximation. Eur. J. Operat. Res., $\quad$ 189: 877-889. DOI: 10.1016/j.ejor.2007.02.058

Eppen, G.D. and R.K. Martin, 1987. Solving multi-item capacitated lot-sizing problems using variable redefinition. Operat. Res., 35: 832-848. DOI: 10.1287/opre.35.6.832

Florian, M. and M. Klein, 1972. Erratum: Deterministic production planning with concave costs and capacity constraints. Manage. Sci., 18: 12-20. DOI: 10.1287/mnsc.18.11.721

Hindi, K.S., 1995. Efficient solution of the single-item, capacitated lot-sizing problem with start-up and reservation costs. J. Operat. Res. Soc., 46: 12231236. DOI: $10.1038 / \mathrm{sj} /$ jors/0461006

Simutis, R., D. Dilijonas and L. Bastina, 2008. Cash demand forecasting for ATM using neural networks and support vector regression algorithms. Proceedings of the 20th EURO Mini Conference on Continuous Optimization and Knowledge-based Technologies, May 20-23, LITHUANIA, Neringa, pp: 416-421.

Simutis, R., D. Dilijonas, L. Bastina, J. Friman and P. Drobinov, 2007. Optimization of cash management for ATM network. Inform. Technol. Control, 36: 117-121.

Wakinaga, H. and K. Sawaki, 2008. A Dynamic lot size model for seasonal products with shipment scheduling. Proceedings of the 7th International Symposium on Operations Research and its Applications, Oct. 31-Nov. 3, Lijiang, China, pp: 303-310.

Wu, T., L. Shi, J. Geunes and K. Akartunali, 2011. An optimization framework for solving capacitated multi-level lot-sizing problems with backlogging. Eur. J. Operat. Res., 214: 428-441. DOI: 10.1016/j.ejor.2011.04.029

Zhang, Z.H., H. Jiang and X. Pan, 2012. A lagrangian relaxation based approach for the capacitated lot sizing problem in closed-loop supply chain. Int. J. Product. Econ., 140: 249-255. DOI: 10.1016/j.ijpe.2012.01.018 